\title{
RESQUEBRAJANDO EL PATRIARCADO EL JUEGO DEL PODER EN LA BALADA DE ALFONSINA BAIRÁN DE ANDRÉS L. MATEO
}

\author{
Giulia De Sarlo \\ Universidad de Sevilla
}

\begin{abstract}
Resumen: La novela dominicana de la dictadura, muy poco conocida fuera de las fronteras del país caribeño, se ha caracterizado en los últimos años por el espacio nuevo que ha sabido dar a los personajes femeninos en su reescritura ficcional de la Era de Trujillo. La balada de Alfonsina Bairán de Andrés L. Mateo es, sin duda, una de las obras más significativas en este sentido.

Palabras claves: novela dominicana, Rafael L. Trujillo, Andrés L. Mateo, mujer, novela prostibularia.

Abstract: The Dominican novel of dictatorship, little known outside the borders of the Caribbean country, has been characterized in recent years by the new space that has given to female characters in its fictional rewriting of Trujillo's Era. The Ballad of Alfonsina Bairán by Andrés L. Mateo is certainly one of the most significant examples of it.
\end{abstract}

Key words: Dominican novel, Rafael L. Trujillo, Andrés L. Mateo, women, brothel novel.

La narrativa dominicana constituye, sin duda, un rincón nebuloso en las letras hispanoamericanas. A quien se ocupa de este olvidado mundo literario del Caribe hispánico ocurre a menudo lo que relataba Rita de Maeseneer hace unos años: "Cuando comento a mis colegas que estoy estudiando la narrativa dominicana, me barajan invariablemente el nombre de la dominicano-americana Julia Alvarez" ${ }^{1}$. Sin embargo, el universo de las letras dominicanas va mucho más allá de la obra de aquellos (pocos) autores que, como Alvarez, han obtenido su fama internacional debido a su estrecha relación con el contexto estadounidense. Una de las plumas, y de las mentes, más relevantes de la dominicanidad actual, es Andrés L. Mateo, poeta, ensayista, educador (ha sido profesor de literatura

${ }^{1}$ R. De Maeseneer, "Algunas calas en la narrativa dominicana de los últimos diez años (19922002/3), en M. Renaud (coord.), República Dominicana ¿Tierra incógnita?, Poitiers, Centre de Recherches Latino-américaines/Archivos, Université de Poitiers, 2005, p. 91. 
hispanoamericana en la UASD y en otras universidades de la capital del país) y sólo marginalmente narrador, aunque precisamente gracias a su obra narrativa recibió el Premio Nacional de Novela en dos ocasiones, en 1981 y en 1991. A este palmarés se añaden el Premio Nacional de Ensayo en 1994, el Premio a la Excelencia Periodística en 1999, y el Premio Nacional de Literatura en 2004, por el conjunto de su trayectoria literaria.

Miguel Ángel Fornerín, uno de los críticos que más se ha interesado por su obra, lo define como un "escritor civil"2, y probablemente no hay mejor manera de resumir su trabajo literario: su obra, en todas sus vertientes, plantea un diálogo constante con la sociedad dominicana, obligándola en su conjunto a reflexionar sobre su pasado, su presente y su futuro. Es fácil intuir, dadas estas premisas, que nuestro autor se haya enfrentado, como muchísimos otros escritores dominicanos, a la dramática experiencia política, social y cultural de los treinta años de la dictadura de Rafael Trujillo, déspota que gobernó el país con mano de hierro entre 1930 y 1961. El tema del trujillato constituye, para la sociedad dominicana, una obsesión de la cual parece no saber desprenderse, quizás sobre todo por la presencia de muchas de las características del régimen en las décadas sucesivas a la caída del dictador, debido a los doce años de presidencia de Joaquín Balaguer ("el trujillato sin Trujillo", como ha sido definido por los historiadores), y después por sus herederos indirectos del PLD, según muchas de las voces del movimiento de oposición al actual gobierno de Danilo Medina. Buscar respuestas en el pasado de la dictadura, a través de la historiografía pero también, de forma tangencial, a través de la ficción literaria, significa para los dominicanos interrogarse sobre el presente: y por eso lleva razón Maryse Renaud cuando, en contra de la opinión corriente, afirma que el del trujillato es para las letras dominicanas "un tema que dista mucho de estar agotado"3.

Andrés L. Mateo se enfrenta al tema del trujillato tanto a través del ensayo como de la narrativa: su análisis crítico más famoso es quizás Mito y cultura en la Era de Trujillo, texto publicado en 1993 que constituye una referencia obligada para quien se acerca al estudio de la realidad dominicana; y tres de sus cuatro obras de ficción se ubican en el contexto cronológico y espacial de la dictadura: su primera novela, Pisando los dedos de Dios, que aparece en 1979; su ficción más reciente, El violin de la adúltera, publicada en 2007; y la tercera, precisamente el texto cuya análisis ocupará las páginas que siguen, La balada de Alfonsina Bairán, cuya primera edición es de 1992.

La balada de Alfonsina Bairán es sin lugar a duda una novela del trujillato. Y poco importa que el dictador casi no aparezca (sólo llegamos a verlo de lejos, acompañando al narrador omnisciente durante un desfile, en el capítulo V): la

2 M. Á. Fornerín, "La ensayística culturalista de Andrés L. Mateo", en M. Renaud (coord.), op. cit., p. 39.

3 "Melancolía criolla y pasión justiciera en La balada de Alfonsina Bairán de Andrés L. Mateo", en M. Renaud (coord.), op. cit., p. 113. 
atmósfera que se respira en cada página de la novela, la oscuridad que penetra cada resquicio de la realidad ficcional, la inmovilidad abúlica en la que se debaten casi todos los personajes de la obra, mientras el resto plantea frustrantes (y frustrados, en la mayoría de los casos) amagos de rebeldía a la dictadura, nos cuenta sobre la Era mucho más que novelas en las que el Jefe se propone como protagonista absoluto. En las garras patriarcales del dictador se debate también la protagonista epónima de la novela, Alfonsina Bairán. La conocemos, en los primeros capítulos, como la joven hija de un inmigrante medioriental, Haffe Bairán, huérfana de madre desde muy temprana edad. La acompañamos en el apaciguado, sereno, casi pasivo descubrimiento del amor cuando su vida se cruza con la de Alberto Cuadras González, un joven exiliado español que llega a la isla después del golpe de estado franquista, junto a tantos otros republicanos. Sabemos de su boda con él; y de cómo de pronto, de un día para otro, el amor de su vida le es arrebatado por los esbirros del régimen, quizás por una palabra de más en las clases donde es maestro, quizás por una actividad subversiva de la que Alfonsina ni siquiera está enterada. Es "la desgracia" a la que la voz del narrador alude desde el comienzo de la novela: el hecho que cambiará el sentido de la vida de Alfonsina para siempre, ya que, después de unos meses de luto rígido y reclusión voluntaria, la existencia de la protagonista da un giro inesperado.

"Alfonsina Bairán murió también, para todos; y resucitó un día, desconocida, pasándose la mano por la frente como para disipar una nube, como si acabara de despertar" (374): ella, el prototipo de mujer pasiva y apaciguada, sumisa sin reticencias a las leyes del patriarcado, cuyos días se sucedían sin demasiadas preguntas y con los únicos faros de la modestia y el decoro, abre las puertas de la casa de familia y la transforma en el Bar de la Turca, el prostíbulo del que será la dueña. Del desconcierto de la comunidad se hace portavoz el narrador omnisciente intradiegético de la historia, un joven estudiante de derecho cuyo nombre desconocemos, y que queda prendado por los misterios que circundan la figura de Alfonsina Barián. Serán sus palabras las que desvelarán poco a poco, en una crónica que tiene tintes unas veces de relato policíaco, otras de poema en prosa, el verdadero sentimiento que ha empujado a la protagonista a cambiar su vida. El burdel es el medio de venganza de Alfonsina Bairán contra el asesino de su marido, un sicario del régimen de Trujillo: es la red que la protagonista, en su fría desesperación, teje alrededor de su presa para transformarlo de victimario en víctima. Una vez conseguido el objetivo, y no es casual, paralelamente a la caída del régimen, el Bar de la Turca ya no tiene razón de ser: él y la misma Alfonsina Bairán desaparecen en una suerte de holocausto final, esfumándose como un sueño en el incendio que una masa enfurecida desata en el establecimiento. Entre las manos del narrador sólo queda el recuerdo (o el sueño, quizás) de una mujer a la que nunca entendió del todo, el diario de ella, que él mismo rescata

${ }^{4}$ Aquí y sucesivamente nos referimos a la edición de la novela de Alianza Editorial (Madrid, 1999). 
del fuego en aquella última, fatídica noche, y el amor de una de las chicas de Alfonsina Bairán, Bartolina, que seguirá a su lado después del que parece ser el final de la Historia.

A la luz de este breve resumen, La balada de Alfonsina Bairán se presenta como un ejemplo muy peculiar de aquel subgénero narrativo que Félix Terrones ha identificado como "novela prostibularia"s. Como escribe Terrones en su ensayo "La imaginación en un burdel. Un sueño latinoamericano hecho ficción: los prostíbulos novelescos"6, si hay algo que caracteriza la literatura hispanoamericana en su conjunto es su capacidad de metaforización del espacio, de creación de lugares tópicos, desde el Macondo de García Márquez hasta la Comala de Juan Rulfo, o el mismo Aleph de Borges, donde lo contingente se hace universal, donde el bic et nunc se transforma en identidad, aunque se trate de una identidad precaria y en constante formación. El burdel, según la teoría de Terrones, es uno de estos espacios metafóricos, liminares, ilícitos y utópicos al mismo tiempo, que recorren de una manera obsesiva el imaginario literario hispanoamericano. "Si se extirpara de la literatura latinoamericana al burdel ésta quedaría desnaturalizada y raquítica ${ }^{7}$, escribió en una ocasión el premio nobel Mario Vargas Llosa: y efectivamente, constata Terrones,

Desde el siglo XIX, cuando las diferentes naciones latinoamericanas comenzaban a despertarse a sus sueños (o pesadillas) republicanos, el prostíbulo ha sido un lugar privilegiado en la representación literaria. Pensemos por ejemplo en novelas de corte naturalista como Santa (1903) del mexicano Federico Gamboa o en novelas donde se muestra un lupanar de bajos fondos, fracasos y miserias como ocurre en El zorro de arriba y el zorro de abajo (1971), del peruano José María Arguedas, o en Los siete locos (1929), del argentino Roberto Arlt ${ }^{8}$.

En su análisis, Terrones toma en consideración cuatro novelas prostibularias (Juntacadáveres (1964) de Juan Carlos Onetti, El lugar sin límites (1965) de José Donoso, La casa verde (1966) y Pantaleón y las visitadoras (1973) de Mario Vargas Llosa), y a través de ellas va evidenciando algunos puntos claves que llevan la

${ }^{5}$ F. Terrones, "Palabra, silencio y subversión en La Casa Verde de Mario Vargas Llosa", ensayo presentado en el seminario Théories et pratiques de la censure, Centre Interuniversitaire de Recherche sur l'Education et la culture dans le Monde Ibérique et Ibéro-américain (CIREMIA), Université François Rabelais - Tours, 11 de abril de 2009 (http://ciremia-tours.blogspot.com. es/2009/06/ateliers-theories-et-pratiques-de-la.html, 25/01/2013). Es una expresión que recurre en varios ensayos del autor, pero que aquí propuso por primera vez.

${ }^{6}$ F. Terrones, "La imaginación en un burdel. Un sueño latinoamericano hecho ficción: los prostíbulos novelescos”, mención especial en la I Bienal Internacional de Ensayo Revista Kipus (Universidad Andina Simón Bolívar, 2011), disponible en http://u-bordeaux3.academia.edu/ F\%C3\%A9lixTerrones (25/01/2013).

7 M. Vargas Llosa, El viaje a la ficción, Madrid, Alfaguara, 2008, p. 170.

8 Terrones, op. cit., 2011, p. 41. 
temática del burdel mucho más allá de un simple factor de contextualización narrativa, transformando así este ámbito literario en un verdadero subgénero. Y se trata de factores que sin duda reconocemos como claves también en el desarrollo narrativo de La balada de Alfonsina Bairán.

En primer lugar, las novelas prostibularias relatan la fundación, desarrollo y derrumbe, por diversas razones, de un burdel en una determinada realidad. El entorno que acoge el prostíbulo es siempre, según Terrones, un espacio periférico, marginal y muerto o moribundo:

La pequeñez y la insignificancia de los lugares en las cartografías, van de la mano con la sensación de vivir a cuentagotas, como si no existiese manera de evadirse a la monotonía de la existencia. En cada una de las novelas, los habitantes parecen destinados a vidas grises y apagadas por culpa de la poca novedad e innovación en sus pueblos o ciudades9.

En el caso de nuestra novela no estamos hablando de la selva peruana, o de una ficcional Santa María, sino de la capital de la República Dominicana; y sin embargo, esta "sensación de vivir a cuentagotas" es más que apropiada al contexto de la dictadura. Leemos por ejemplo en el primer capítulo, en voz de la propia Alfonsina:

Los domingos paseábamos alrededor de la glorieta del parque, mientras la banda del Consejo Municipal entonaba el concierto. Era un ritual, una carnada, una escaramuza que el convencionalismo permitía. (17)

Y también, referiéndose al marido:

Entré en su vida saliendo de mis lágrimas [...] puesto que yo no era una mujer, sino una máscara. Se actuaba y se vivía circundada por esta soledad. Por ese limbo, por esa carencia de pasado. (19)

El segundo factor evidenciado por Terrones tiene que ver con la reacción de los actores sociales de ese contexto pasivo que de pronto se ve revolucionado por la fundación del burdel. Nadie se queda indiferente: la sociedad se parte en dos bandos, quienes apoyan, por la razón que sea, la novedad, y quienes se oponen fundamentalmente a la inmoralidad del nuevo lugar. La bandera de la lucha en contra del prostíbulo, en todas las novelas analizadas por Terrones, es izada en primera instancia por un miembro de la iglesia: y es lo que pasa también en el caso de Alfonsina Bairán, contra la cual el padre Luis, de la parroquia cercana, organiza piquetes y manifestaciones, con la esperanza de aniquilar en el corazón

${ }^{9}$ Ibid., p. 5. 
de la viuda "la resolución que envejeció su rostro y que la llevó a atropellar todas sus virtudes, y a convertirse en una dama indigna” (28-29):

en el barrio fue una descomunal grosería que obligó a constituir un comité de moralización barrial, bajo la presidencia del padre Luis, y un grupo de redacción que escribía, por lo menos, semanalmente a la sección El Foro Público, del periódico El Caribe. Se organizaron veladas santas destinadas a hacer conciencia sobre el peligro que se cernía contra el vivir cotidiano, y más de una vez, unas poco triunfales procesiones recorrieron las calles bullangueras con unas beatas enloquecidas que agitaban unos mantos sagrados con la imagen de la Virgen de Altagracia. (40)

Sin embargo, su supervivencia es garantizada por el apoyo de otros estratos de la población: son los más jóvenes, quienes ven en el prostíbulo la puerta para llegar a un cielo desconocido. Es el caso, en la novela que analizamos ahora, del narrador, el joven e innominado estudiante de derecho que casi a su pesar va uniendo su destino al de Alfonsina Bairán. Para él, el bar se transforma en un refugio, en un espacio casi sagrado, alejado de la rutina humillante de la dictadura, y donde además - paradojas de una ficción tan cercana, en ocasiones, a la realidad - encuentra el amor: la joven prostituta Bartolina, con la que tiene probablemente sus primeras experiencias sexuales y en la que se refugia en los momentos más difíciles. Sin embargo el apoyo externo al burdel, el apoyo que de verdad garantiza su supervivencia, es el apoyo del poder. Es algo que Terrones subraya sobre todo en el caso de El lugar sin límites, pero que se explicita también en La balada de Alfonsina Bairán: el Bar de la Turca se llena rápidamente de calíes y miembros más o menos preeminentes del régimen. Es eso lo que Alfonsina buscaba, ya que su primer objetivo es el de vengar al marido; y es lo que llevará a la masa anónima y feroz del capítulo XII, una vez muerto Trujillo, a pegar fuego al Bar. El burdel está tan vinculado al régimen que, al desaparecer éste, no puede perdurar, y se desmorona entre cenizas.

El tercer factor que aúna a las novelas prostibularias, fundamental por lo que nos concierne, es el parecido entre todos los fundadores de los burdeles de estas ficciones. Todos, según Terrones, vienen de fuera, son extraños a la comunidad: algo que ocurre también en el caso de Alfonsina, en el momento en que se desprende de sus apellidos de mujer casada (Cuadra González, apellidos explícitamente peninsulares) y reivindica sus orígenes recuperando su nombre de soltera, Bairán. Solamente en la última página de la novela el narrador se referirá a la protagonista sólo con su nombre de pila: en todos los demás casos el apellido medioriental será una bandera asociada a su nombre. Es más, Alfonsina llamará a su local "El bar de la Turca", como queriendo subrayar ulteriormente su distancia respecto al mundo hispanófilo que la rodea.

Todos los proxenetas, además, se caracterizan por tener una fuerza interior casi sobrehumana, un temple único, que les anima a luchar contra las dificultades 
para llevar adelante su empresa: algo que desde luego no falta en Alfonsina, que sola contra el mundo y sus reproches, cada noche menos el martes, abre las puertas de su casa a la hombría dominicana en busca de emociones.

Pero quizás la característica más interesante que aúna a los fundadores es el halo de misterio que los rodea:

Mientras los futuros proxenetas preparan la instalación de sus locales, el misterio determina sus conductas, dándoles un aura de personas extravagantes o alienadas. [...] El hecho de que se caracterice a los futuros proxenetas como individuos fuera de lo común, por sus cualidades físicas y morales, pero también por sus actitudes inexplicables y secretas, no hace más que reforzar el interés entorno a la fundación de los lupanares. Por eso, la aparición efectiva del prostíbulo adquiere los contornos de una proeza, consecuencia de la intersección de numerosos esfuerzos, sí, pero sobre todo resultado del ardor y la vehemencia de sus fundadores ${ }^{10}$.

Alfonsina está envuelta en el misterio no sólo en la fase previa a la apertura del burdel: si hay algo que la caracteriza a lo largo de toda la novela, son precisamente sus aparentes contradicciones, su alienación respecto al rol que ha elegido para sí misma dentro de la sociedad. El Bar de la Turca es un prostíbulo, sí, pero en él no se practica sexo: las chicas viven allí, y allí, en el contexto etílico del bar, por decirlo así, encuentran a sus clientes; sin embargo, para trabajar tienen que ir a un hotel cercano, el hotel Saratoga - y no antes de haber obtenido de Alfonsina Bairán una suerte de permiso, en un ritual casi nupcial: el pretendiente pide la chica a Alfonsina, y ella la llama, le pone una flor de plástico en el pelo y la deja ir:

Los hombres hablaban con ella; situados estratégicamente en un nivel inferior, se veían como arrodillados, como humillados. Pero ella desovillaba una sonrisa irreconocible y movía un dedo, o llamaba suavemente a la muchacha asediada, y le alisaba el pelo brevemente, como para protegerla del ultraje, hasta que le colocaba la rosa roja, de plástico, con lo que yo pensé era un cierto desagrado del alma. (43)

Además, Alfonsina Bairán parece todo menos que una alcahueta:

Su traje negro que remataba en un cuello señorial de encajes, sus ojos vivaces, su bastón con arcángeles, recostado en un extremo de la caja registradora; sus cabellos negros recogidos en un moño aristocrático. [...] Me dediqué a observarle a la dama sus ínfulas de estatua. Era como si ante su presencia todos estuvieran arrodillados. (42-43)

10 Ibid., p. 7. 
Y su silencio, sus palabras absolutamente medidas, se alejan mucho de los silencios de otros personajes de burdel. Pienso sobre todo en la Chunga, en su papel en La casa verde, pero más aún en la obra teatral homónima que Vargas Llosa estrenó en 1986. En las acotaciones leemos su descripción:

Su físico, su severidad, su laconismo, intimidan; es raro que los borrachos traten de sobrepasarse con ella. No acepta confianzas ni galanterías; no se le conoce novios, ni amistades. Parece decidida a vivir siempre sola, dedicada en cuerpo y alma a su negocio. Si se exceptúa la brevísima historia con Mechebastante confusa para los clientes, por lo demás- no se sabe de nada ni de nadie que haya alterado su rutina. En la memoria de los piuranos que frecuentan el lugar, ella está, siempre, seria e inmóvil detrás del mostrador ${ }^{11}$.

E1 silencio de la Chunga, su laconismo, es, como el de Alfonsina Bairán, casi una barrera infranqueable. Félix Terrones, en su artículo "Palabra, silencio y subversión en La casa verde de Mario Vargas Llosa”, afirma que

En las novelas prostibularias latinoamericanas se plantea en múltiples niveles los conflictos de género. Uno de ellos es el del acceso, uso y ejercicio pero también renuncia y despojo de la palabra. En principio podríamos pensar que en las novelas de prostíbulos y/o meretrices, los personajes femeninos ocupan un lugar relevante y protagónico marcado, en ocasiones, ya desde el título: Juana Lucero (1902), Santa (1903), Nacha Regulez (1919), La reina Isabel cantaba rancheras (1994). Sin embargo los personajes femeninos poseen en estos textos un lugar problemático que conjuga, a la vez, sometimiento y transgresión ${ }^{12}$.

El crítico reconoce entonces una función transgresora femenina a través del silencio: las protagonistas femeninas son capaces de poner en entredicho "las jerarquías y las dominaciones masculinas, castrándolas simbólicamente"13. Es lo que también sostiene Elena Watnicki Echevarría, cuando afirma que la Chunga, junto a otros personajes femeninos teatrales del corpus vargallosiano, lleva a cabo una suerte de "rebelión silenciosa"14: su defensa de la fuerza física masculina, como nota también Elena Guichot ${ }^{15}$, es el silencio, y junto a él el convertirse en propietaria de un bar, con una independencia económica que explicita el poder sobre el resto del grupo.

11 M. Vargas Llosa, Teatro. Obra reunida, Madrid, Alfaguara, 2006, p. 264.

12 Terrones, op. cit., 2009.

13 Ibídem.

${ }^{14}$ Cfr. E. Watnicki Echevarría, La significación de la mujer en la narrativa de Mario Vargas Llosa, tesis doctoral, Universidad Complutense de Madrid, 1993, p. 422 ss.

15 Cfr. E. Guichot Muñoz, La dramaturgia de Mario Vargas Llosa. Contra la violencia de los años ochenta, la imaginación a escena, Sevilla, Universidad de Sevilla/Diputación Provincial de Sevilla, 2011, sobre todo el capítulo "El erotismo: escritura y sexualidad en La Chunga", pp. 117-192. 
En el caso de Alfonsina Bairán, sin embargo, el uso del silencio parece tener razones y finalidades distintas. Evidentemente para Alfonsina el silencio es un medio para ganarse el respeto de sus clientes, marcando su distancia respecto al bullicio del burdel; pero es también una manera de ganar su confianza, y a través de ésta, de dominarlos y poder llevar a cabo su plan principal: la venganza de su marido. Es ésta la verdadera, única finalidad de la protagonista de la novela de Mateo, y en este sentido el espacio del Bar de la Turca llega a ser un espacio utópico, liminar: en su burdel Alfonsina recrea el mundo decaído y perverso de la dictadura, pero lo plasma, lo amolda a sus necesidades. Lo purifica en la medida de lo posible (de allí el trato profundamente maternal que tiene con Bartolina y las demás chicas), lo domina desde su posición de superioridad moral, a través del silencio, y superioridad física, gracias a la posición real, tangible, en la que se ubica en el Bar. Alfonsina se apodera de ese mundo y le obliga, sutil pero físicamente, a mirarse a la cara. La crítica no ha evidenciado hasta el momento la aparición recurrente del espejo en la novela: el gran espejo en el centro del bar, por ejemplo, en el que las chicas y los clientes están casi obligados a mirarse nada más entrar al local, se encuentra allí para reflejar, como escribe Jean Chevalier, "la verdad, la sinceridad, el contenido del corazón y de la conciencia, bueno o malo que sea"16.

Todo, en esta réplica del mundo exterior que es el Bar de la Turca, todo tiene su significado, y cada persona involucrada es en realidad un personaje con un papel preciso: la teatralidad de este espacio calculadísimo, evidenciada sutilmente desde el comienzo de la novela, tiende inmancablemente hacia la voluntad de Alfonsina. Como resume al narrador quizás el único amigo de Alfonsina, el abogado Eleuterio Cordones, ya al final de la novela,

"Todo [...] usted, yo, el bar y las putas estábamos al servicio de ella. [...] Fue la venganza, la venganza de ella, que era una suma de debilidades, la venganza que la liberó ahora del espejo de la memoria en el que estaba atrapada, de la memoria en que permanecía fija para siempre la escena del crimen inexplicable del marido"17. (156)

Resulta evidente entonces que el silencio de Alfonsina es mucho más que una defensa: es un ataque, a la espera de la ocasión propicia para dar el tiro de gracia.

Es significativo, de hecho, que a diferencia de un personaje como la Chunga, Alfonsina no se reserve mínimamente la posibilidad de comunicar su interioridad: abrirá su corazón con Eleuterio Cordones, quizás el único que pueda realmente entenderla ya que los esbirros de Trujillo le han quitado a un

16 J. Chevalier, Dizionario dei simboli, vol. 2, Milano, Biblioteca Universale Rizzoli, 1997, p. 414 (mía la traducción).

17 Mía la anotación en negrita. 
hijo; lo hará de alguna forma con el joven narrador, al que adopta casi como a un hijo (de "hijo simbólico" y "amante platónico" habla Maryse Renaud ${ }^{18}$, aunque me permito discrepar respeto a la última definición); y, quizás, lo más significativo, lo hará constantemente consigo misma, a través de las páginas del diario que la acompaña desde antes de casarse y que el narrador recuperará entre las llamas del incendio final, catártico, en el que desaparece el Bar de la Turca.

El diario es un elemento recurrente en la narrativa de Mateo, y no necesariamente relegado al ámbito femenino: en El violín de la adúltera, su novela más reciente también ambientada en plena dictadura, en los años 50, es el protagonista, un hombre, el que se adueña de este instrumento subjetivo por excelencia. Más todavía que en sus silencios, entonces, es en la palabra escrita donde reside explícitamente la reivindicación de poder de Alfonsina frente a este mundo patriarcal que la quisiera pasiva, callada, víctima de los acontecimientos y por qué no, rebajada sua sponte al submundo del burdel. Y eso sí, el joven narrador lo entiende perfectamente: en el diario, en su subjetividad puesta negro sobre blanco está lo único que realmente hace falta entender de la vida de Alfonsina Bairán: su amor infinito por el hombre que le fue quitado.

Cuando salí [del bar en llamas], la lluvia leve se había como detenido en el techo de la noche, y la multitud dispersándose era un montón de semblantes desfigurados, con los cabellos humedecidos y los rumores y las voces apagándose en el aire. [...] Y yo toqueteaba bajo la camisa el testimonio palpitante del Diario de su vida, la libreta deshojada y sin explicación posible de los poemas que quizás él nunca escribió, y la foto de pie, junto al muro, en la que ella lo miraba desleída, en su ayer de muchacha, y él le sonreía con la luz de aquel tiempo, cuidando de quedarse ahí detenido, arañando la eternidad, colmando la sensación de invadida por ese fulgor que arrancó del amor, y que, ahora estaba seguro, fue el don de su vida. (148)

Quizás sea eso, la confianza en el poder de la palabra más todavía que las experiencias anecdóticas de lo vivido (me refiero por ejemplo a la lucha antitrujillista que el joven también lleva a cabo por su cuenta), lo que más llega a unir a Alfonsina Bairán con el narrador; como bien apunta Renaud, "sin Alfonsina, símbolo del poder del Verbo, de la fabulación, nada podría existir: ni el enclave mitificado del burdel [...] y menos aún el mismo narrador". ${ }^{19}$

18 En M. Renaud (coord.), op. cit., p. 117.

19 Ibid., p. 123. 


\section{BIBLIOGRAFÍA}

Mateo, Andrés L., La balada de Alfonsina Bairán, Madrid, Alianza Editorial, 1999.

Chevalier, Jean, Dizionario dei simboli, Milano, Biblioteca Universale Rizzoli, 1997.

De Maeseneer, Rita, "Algunas calas en la narrativa dominicana de los últimos diez años (1992-2002/3), en Maryse Renaud (coord.), República Dominicana ¿̇Tierra incógnita?, Poitiers, Centre de Recherches Latino-américaines/Archivos, Université de Poitiers, 2005, pp. 91-111.

Fornerín, Miguel Ángel, “La ensayistica culturalista de Andrés L. Mateo”, en Maryse Renaud (coord.), República Dominicana i̇Tierra incógnita?, Poitiers, Centre de Recherches Latino-américaines/Archivos, Université de Poitiers, 2005, pp. 39-61.

Guichot Muñoz, Elena, La dramaturgia de Mario Vargas Llosa. Contra la violencia de los años ochenta, la imaginación a escena, Sevilla, Universidad de Sevilla/Diputación Provincial de Sevilla, 2011.

Renaud, Maryse, "Melancolía criolla y pasión justiciera en La balada de Alfonsina Bairán de Andrés L. Mateo", en Maryse Renaud (coord.), República Dominicana ¿́Tierra incógnita?, Poitiers, Centre de Recherches Latino-américaines/Archivos, Université de Poitiers, 2005, pp. 113-123.

Terrones, Félix, "Palabra, silencio y subversión en La Casa Verde de Mario Vargas Llosa", seminario Théories et pratiques de la censure, Centre Interuniversitaire de Recherche sur l'Education et la culture dans le Monde Ibérique et Ibéro-américain (CIREMIA), Université François Rabelais - Tours, 11 de abril de 2009 (http:// ciremia-tours.blogspot.com.es/2009/06/ateliers-theories-et-pratiques-de-la.html, 25/01/2013).

Terrones, Félix, "La imaginación en un burdel. Un sueño latinoamericano hecho ficción: los prostíbulos novelescos", mención especial en la I Bienal Internacional de Ensayo Revista Kipus (Universidad Andina Simón Bolívar, 2011), disponible en http://u-bordeaux3.academia.edu/F\%C3\%A9lixTerrones (25/01/2013).

Vargas Llosa, Mario, El viaje a la ficción, Madrid, Alfaguara, 2008.

Watnicki Echevarría, Ellen, La significación de la mujer en la narrativa de Mario Vargas Llosa, tesis doctoral, Universidad Complutense de Madrid, 1993.

$\begin{array}{ll}\text { Nombre del autor: } & \text { Giulia De Sarlo } \\ \text { Dirección-e: } & \text { gdesarlo@yahoo.com } \\ \text { Dirección postal: } & \begin{array}{l}\text { Calle Cascáis 3, 10 C, 41089, Montequinto } \\ \text { (Sevilla) }\end{array}\end{array}$

Fecha de recepción: 01/02/2013

Fecha de aceptación: 06/10/2013 
